\title{
Präsidiumswahlen der DMV
}

Die neuen Präsidiumsmitglieder stehen fest: Bei den DMVPräsidiumswahlen im August/September 2020 kam es nach Auszählung der Stimmen am 5. Oktober 2020 zu folgendem Ergebnis:

Auf die drei Präsidiumsplätze, die mit einer besonderen Funktion verbunden sind und daher separat zur Abstimmung stehen, wurden gewählt:

- PD Dr. Gudrun Thäter, KIT Karlsruhe; sie wird die neue Herausgeberin der DMV-Mitteilungen und damit auch Mitglied des Vorstands;

- Prof. Dr. Alexander Zimmermann, Université de Picardie, wird der neue Herausgeber des DMV-Jahresberichts;

- Prof. Dr. Etienne Emmrich, TU Berlin, wurde im Amt als Schatzmeister und Mitglied des Vorstands bestätigt.

Die beiden weiteren Präsidiumsplätze gehen an:

- Prof. Dr. Anke Pohl, Universität Bremen

- Prof. Dr. Thomas Schick, Universität Göttingen

Den Wahlausschuss bildeten Prof. Dr. Dirk Werner (FU Berlin), Prof. Dr. Jürg Kramer, ehemaliger DMV-Präsident (HU Berlin), und Andrea Kirstin-Gaekel (DMV-Geschäftsstelle). Bei der Stimmenauszählung am Nachmittag des 5. Oktober 2020 an der FU Berlin wurden sie von Thomas Vogt (DMV-Medienbüro), Beate Klompmaker (DMVNetzwerkbüro) sowie den studentischen Hilfskräften Malte Leimbach und Marc Oprisiu unterstützt.

Insgesamt wurden $45^{2}$ Stimmzettel rechtzeitig eingereicht, die alle gültig waren.

\begin{tabular}{ll}
\hline Abgegebene Stimmen für & \\
\hline Prof. Dr. Etienne Emmrich (Technische Universität Berlin) & 426 \\
PD Dr. Gudrun Thäter (KIT Karlsruhe) & 415 \\
Prof. Dr. Alexander Zimmermann (Université de Picardie) & 417 \\
Prof. Dr. Heike Faßbender (Universität Braunschweig) & 259 \\
Prof. Dr. Anke Pohl (Universität Bremen) & 300 \\
Prof. Dr. Thomas Schick (Universität Göttingen) & 290 \\
\hline
\end{tabular}

Das Präsidium der DMV wählte am 16.5. als Präsidentin Prof. Dr. Ilka Agricola (Universität Marburg) mit 7-6 Stimmen und am 28.9. als Vizepräsidenten Prof. Dr. Joachim Escher (Universität Hannover) einstimmig für die jeweils zweijährige Amtszeit ab 1.1.2021.

Durch die Wahl des Präsidiumsmitglieds Ilka Agricola zur DMV-Präsidentin wird ihr Präsidiumsplatz frei, auf den nach der Wahlordnung der DMV (siehe tinyurl. com/y2pu8ave, 3e) Prof. Dr. Heike Fassbender (TU Braunschweig) nachrückt.
„Ich danke den Kollegen, die aus dem Präsidium ausscheiden, sehr herzlich für ihr jahrelanges Engagement für die DMV und gratuliere den neuen Präsidiumsmitgliedern zu ihrer Wahl! Ich heiße sie im DMV-Präsidium sehr herzlich willkommen und freue mich auf die Zusammenarbeit“, sagte DMV-Präsident Friedrich Götze nach Auszählung der Stimmen und ergänzte: „Ebenso freue ich mich, dass Etienne Emmrich weiter Schatzmeister der DMV bleibt; auch ihm gratuliere ich herzlich zur Wahl!“

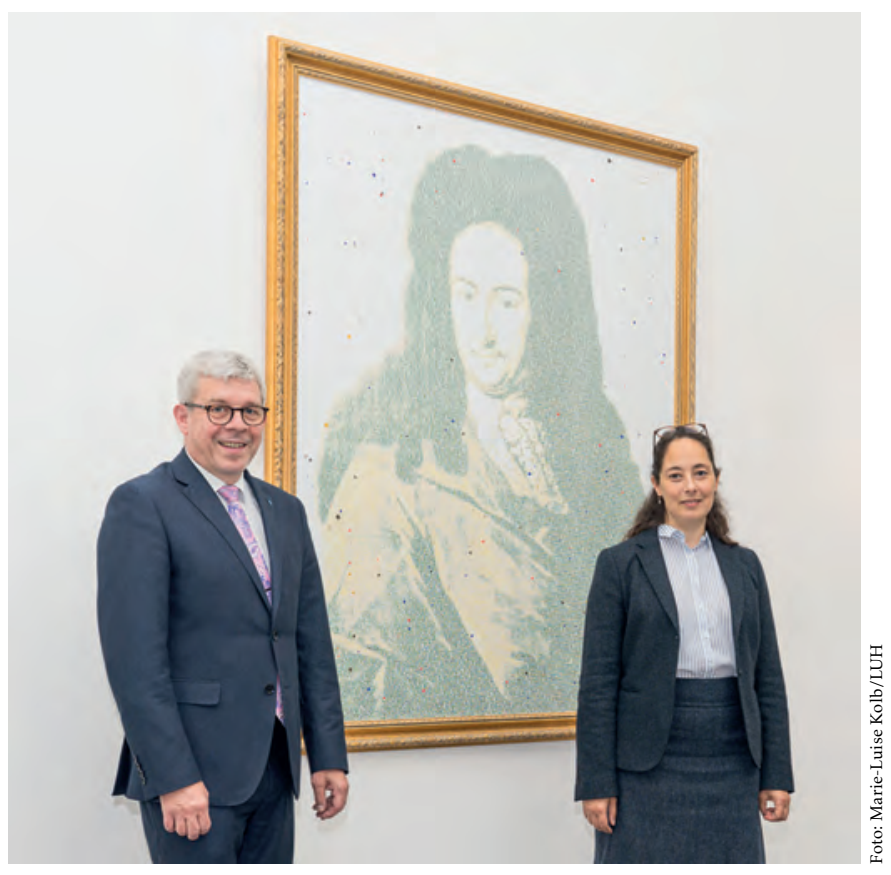

Ilka Agricola und Joachim Escher,

Präsidentin und Präsident der DMV ab 2021 